\title{
Chronic pulmonary paracoccidioidomycosis masquerading as lymphangitis carcinomatosa
}

\author{
SIMON BOWLER, ASHLEY WOODCOCK, PHILIP DA COSTA, \\ MARGARET TURNER-WAR WICK
}

From the Brompton Hospital, London

Many pulmonary disorders may produce a non-specific granulomatous reaction. We describe a case of unsuspected chronic pulmonary paracoccidioidomycosis that emphasises the importance of performing fungal stains on lung biopsy specimens in all cases where an interstitial granulomatous reaction is present without an obvious cause.

\section{Case report}

A 57 year old caucasian female clerk was admitted for investigation of possible lymphangitis carcinomatosa. She complained of cough and of breathlessness and wheeze on exertion, which had developed gradually over a period of three years. Four years earlier she had had a left mastectomy

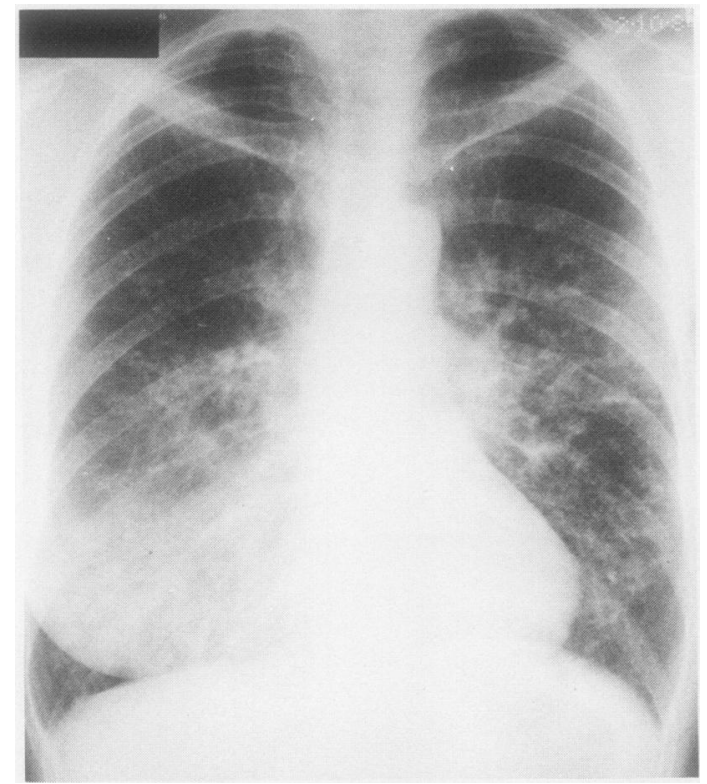

Fig 1 Chest radiograph showing reticular shadowing in mid and lower zones and left mastectomy site.

Address for reprint requests: Dr A Woodcock, Brompton Hospital, London SW3 6HP.

Accepted 10 June 1985 for an intraduct carcinoma of the breast; this was grade $\mathrm{Tl} \stackrel{\oplus}{\rightarrow}$ $\mathrm{N}_{0} \mathbf{M}_{0}$, although at subsequent follow up she had not devel- $\overrightarrow{-}$ oped clinical metastatic disease. She had smoked cigarettes $N$ (total 60 pack years). She had worked as a clerk in Buenos Aires (1961-4) and Caracas (1965-7) but had not revisited South America in the last 17 years.

There were no abnormalities on examination. Investigations showed: haemoglobin $15.7 \mathrm{~g} / \mathrm{dl}$; white cell count $8.3 \times 10^{9} / 1$ (differential count neutrophils $65 \%$, eosinophils $4 \%$, lymphocytes $28 \%$, monocytes $3 \%$ ); erythrocyte sedimentation rate $17 \mathrm{~mm}$ in one hour; blood urea and electrolyte concentrations normal; liver function normal; serum calcium normal; aspergillus and avian precipitins negative; serum angiotensin converting enzyme activity 83 (reference range $16-52) \mathrm{nmol} \mathrm{ml}^{-1} \mathrm{~min}^{-1}$.

A chest radiograph showed diffuse bronchocentric interstitial shadowing in both mid and lower zones (fig 1). Retro-

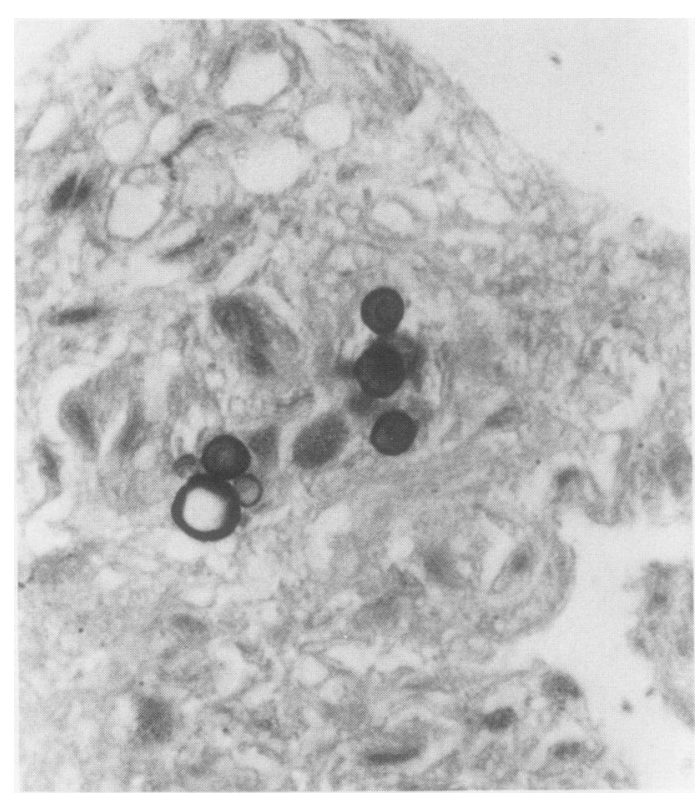

Fig 2 Transbronchial biopsy specimen stained by the Gomori-Grocott methenamine silver technique shows a yeast with multiple narrow necked buds, typical of Paracoccidioides spp. ( × 1080.) 
spective assessment of chest radiographs taken in 1981 showed similar but less prominent shadowing. Pulmonary function testing showed: FEV $_{1} 1.35$ litres $(62 \%$ predicted normal); forced vital capacity (FVC) 2.33 litres ( $80 \%$ predicted); total lung capacity (TLC) 4.82 litres (102\% predicted); transfer factor (TLCO) $2.75 \mathrm{mmol} \mathrm{min} \mathrm{min}^{-1} \mathrm{kPa}^{-1}$

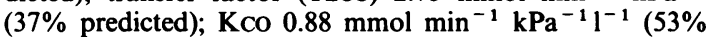
predicted). Examination of sputum for malignant cells and acid fast bacilli was negative.

Fibreoptic bronchoscopy was performed. There were no endobronchial abnormalities. Transbronchial biopsy showed patchy chronic interstitial inflammation with poorly formed epithelioid and giant cell granulomas. Stains for acid fast bacilli were negative, but within the granulomas a Grocott methenamine silver preparation demonstrated budding yeast forms of a fungus with the morphological appearances of Paracoccidioides braziliensis (fig 2). The diagnosis of paracoccidioidomycosis was confirmed by a positive precipitin test (titre 1/128; Mycological Reference Laboratory, Atlanta, Georgia).

\section{Discussion}

Paracoccidioidomycosis (or South American blastomycosis) is a systemic mycosis caused by Paracoccidioides braziliensis and endemic in many parts of South America. It affects mainly agricultural workers with a male:female ratio of 50:1. Cases have been divided into four groups ${ }^{1}$ : (a) acute pulmonary - with multiple cavitating lesions mimicking tuberculosis; (b) chronic pulmonary - with a progressive fibrosis affecting both lower zones; (c) acute disseminatedwith skin papules, gastrointestinal infiltrations, rectal bleeding, lymphadenopathy, and hepatosplenomegaly; (d) chronic disseminated - with oral ulceration and lymphadenopathy.

Types $(a)$ and $(c)$ are rapidly fatal if untreated but types (b) and (d) run a course over many years. The diagnosis is made by smear examination and culture of the morphologically distinct budding yeast forms of $\boldsymbol{P}$ braziliensis from sputum or oral ulcers, and is confirmed serologically by complement fixation tests. Treatment, which was relatively unsuccessful with amphotericin and sulphonamides, has been revolutionised by the introduction of ketoconazole, which has improved the response rate from $50 \%$ to $95 \%{ }^{2}$
The patient described here is atypical, being a female urban dweller. She falls into clinical category (b) (chronic pulmonary) with a latent period of at least 17 years. Nine cases of chronic pulmonary or disseminated paracoccidioidomycosis have been described in the United States. ${ }^{3}$ All the patients were men, had lived in South America or Mexico, and had latent periods of from three to 20 years after leaving the endemic area. Our patient had raised activity of serum angiotensin converting enzyme. Although this has been documented in a range of granulomatous conditions, including some fungal diseases, ${ }^{4}$ we believe this is the first report of increased serum angiotensin converting enzyme activity in paracoccidioidomycosis.

We believe that this case illustrates two important points. Firstly, it is essential to carry out silver stains for fungi on biopsy material in any patient with an unknown granulomatous condition, especially when the patient has visited an area where a systemic mycosis is endemic. Secondly, in a patient with a resected breast carcinoma causes of reticular basal shadowing other than lymphangitis carcinomatosa should be considered, especially when there is no additional evidence of metastatic disease.

We would like to thank Dr R Hay for his advice on diagnosis and management.

\section{References}

1 Londero AT, Ramos CD. Paracoccidioidomycosis: a clinical and mycologic study of forty-one cases observed in Santa Maria, RS, Brazil. Am J Med 1972;52:771-5.

2 Restrepo AA, Gemel I, Cano L, et al. Treatment of paracoccidioidomycosis with ketoconazole: a three year experience. Am J Med 1983;74:48-52.

3 Murray HW, Littman ML, Roberts RB. Disseminated paracoccidioidomycosis (South American blastomycosis) in the United States. Am J Med 1974;56:209-20.

4 Ryder KL, Jay SJ, Kiblawi SO, Hull ML. Serum angiotensin converting enzyme activity in patients with histoplasmosis. JAMA 1983;249:1888-9. 